\title{
Pittsburgh, North Carolina Sections Announce New Officers
}

The Greater Pittsburgh and North Carolina Sections of the Materials Research

Society both recently elected new slates of officers for 1993:

\author{
Greater Pittsburgh Section \\ President \\ John Basil \\ PPG Industries \\ Glass Research and Development \\ Center \\ P.O. Box 11472 \\ Pittsburgh, PA 15238 \\ Vice President \\ Michael E. McHenry \\ Carnegie Mellon University \\ Dept. of Materials Science and \\ Engineering \\ Pittsburgh, PA 15213 \\ Secretary \\ Ian Nettleship \\ University of Pittsburgh \\ Dept. of Materials Science and \\ Engineering \\ Pittsburgh, PA 15213 \\ Treasurer \\ Prashant Kumta \\ Carnegie Mellon University \\ Dept. of Materials Science and \\ Engineering \\ P'ittsburgh, PA 15213
}

\section{UNIVERSITY CHAPTER NEWS}

\section{Berkeley Holds First Graduate Student Poster Session}

The Materials Research Society student chapter at the University of CaliforniaBerkeley recently sponsored its first annual graduate student poster session. Held March 10-11, 1993, the event was presented in conjunction with the College of Engineering's Industrial Liaison Program, in which representatives from industry are invited to campus to learn about the research conducted at Berkeley.

At the poster session, graduate stu-

\author{
North Carolina Section \\ President \\ Max Swanson \\ University of North Carolina \\ Dept. of Physics and Astronomy \\ Chapel Hill, NC 27599 \\ Vice President \\ Nalin Parikh \\ University of North Carolina \\ Dept. of Physics and Astronomy \\ Chapel Hill, NC 27599 \\ Secretary \\ John Posthill \\ Research Triangle Institute \\ P.O. Box 12194 \\ 3040 Cornwallis Road \\ Research Triangle Park, NC 27709 \\ Treasurer \\ Orlando Auciello \\ MCNC Center for Microelectronics \\ 3021 Cornwallis Road \\ Research Triangle Park, NC 27709
}

dents from various departments displayed their materials-related research. The authors were present at their respective posters during lunchtime both days to discuss their work with industry representatives, faculty, and other students. An abstract booklet prepared by the chapter also was available.

Because the session was well-received, the posters were displayed for an additional week.
Expand your MRS Membership Benefits by Joining or Starting an MRS Section!

\section{Section Benefits include-}

- Complimentary copies of MRS Bulletin (monthly)

- Cash support for special projects

Mailing lists, graphics, and other in-kind services

Access to videotape library for professional development programs

Speaker assistance (including Turnbull Lecturer)

And more...

\section{Current MRS Sections}

Alabama

East Tennessee

Greater Pittsburgh

New Mexico

North Carolina

North Texas

Washington/Baltimore

Western New York

For more information on the Section nearest you, or to find out how to start a Section, call Anne Wagner at (412) 367-3003; fax (412) $367-4373$. 